\title{
Older women, breast cancer, and social support
}

\author{
Grace J. Yoo • Ellen G. Levine • Caryn Aviv • \\ Cheryl Ewing • Alfred Au
}

Received: 30 May 2009 / Accepted: 26 October 2009/Published online: 22 November 2009

(C) The Author(s) 2009. This article is published with open access at Springerlink.com

\begin{abstract}
Introduction One in ten women over the age of 65 will develop breast cancer. Despite this high incidence of breast cancer among older women, social support for them is often inadequate. This paper describes a qualitative study of the impact of a breast cancer diagnosis on older women from racially/ethnically diverse populations and their subsequent need for social support.

Methods Forty-seven older African American, Asian American, Caucasian and Latina women between the ages of 65 to 83 participated in a larger study examining the impact of breast cancer on women from racially/ethnically diverse populations and the meaning and nature of social support. The women completed an in-depth qualitative interview on the psychosocial impact of breast cancer and the meaning and nature of social support.

Results and Conclusion The results indicate that there are variations in reactions to a breast cancer diagnosis among older women, and that these reactions impact their experiences with seeking social support at diagnosis and during treatment. Respondents were concerned about their
\end{abstract}

G. J. Yoo $(\bowtie) \cdot$ E. G. Levine

San Francisco State University,

San Francisco, CA, USA

e-mail: gracey@sfsu.edu

C. Aviv

University of Denver,

Denver, CO, USA

C. Ewing $\cdot$ A. Au

UCSF Comprehensive Cancer Center,

San Francisco, CA, USA aging bodies, potential dependency on others, and loss of autonomy. At the same time, the severity of cancer treatment and existing co-morbidities often meant they needed to learn to receive support, and to reach out if they had no support. The implications of these findings underscore the older cancer patient's need to strengthen her supportive networks at the time of diagnosis, during treatment, and post-treatment.

Keywords Breast cancer - Ductal cancer in situ - Older women Social support

\section{Introduction}

In the USA, breast cancer is the most commonly diagnosed form of cancer for women and is one of the leading causes of morbidity and mortality for women, regardless of ethnic background [1]. Advancing age is the single most critical risk factor in the development of breast cancer, and one in ten women over the age of 65 will develop it [1, 47]. Unlike younger breast cancer survivors, older breast cancer survivors face issues of advancing age and more comorbidities [45] that may result in more side effects from treatment and more complicated recovery $[8,36,40,45,46$, $50,52]$. Recent studies have indicated that the toxicity of chemotherapy, such as the side effects of fatigue and nausea, appear more often in older women than in younger women [40].

Older women and reactions to breast cancer

Even though there is an increased risk of breast cancer among older women, there is comparatively little literature 
on the psychosocial impact of a breast cancer diagnosis and its subsequent treatment on older women [50]. What is also known is that older women face under-treatment for cancer in areas including chemotherapy, radiation, palliative care, pain management, and reconstruction [8]. For most individuals, a cancer diagnosis is often accompanied by fear of death, loss of control, isolation, hopelessness, and depression $[16,23,24,29]$. Older adults with cancer are more distressed if they also experience functional decline as a result of their cancer diagnosis and treatment [26]. Research has shown that when faced with a breast cancer diagnosis and its subsequent treatments, older women have fewer supportive networks to rely on [41] than younger women. These factors can impact the older woman's psychosocial reaction to a breast cancer diagnosis [46].

\section{Social support and breast cancer}

Social support is characterized as any combination of emotional, tangible, appraisal, and informational support [12]. Support can be formal, informal, social, professional, structured, or unstructured [25]. It has been recognized for many years that social support is an important factor which may affect the general well-being of individuals living with chronic and life-threatening health conditions like breast cancer [13]. Social support can help women with breast cancer to adjust and cope, and can have positive impacts on the survivor's health $[6,7,22,31,48]$. For an individual who has completed treatment, social support can enhance her quality of life and ease her transition into life after treatment [32]. For breast cancer survivors, access to a supportive environment can prevent long-term psychological difficulties and benefit her general well-being [29, 42]. Unfortunately for older women, most studies examining the role of social support for women diagnosed with breast cancer have so far focused on the experience of younger women [7].

Older breast cancer survivors and social support

Compared to older women without breast cancer, and without other illnesses, older women diagnosed with breast cancer face a decrease in quality of life and psychological well-being [45]. Among the elderly, increasing comorbidities, limited financial support, poor physicianpatient communication, and limited social support are often associated with depression [51]. Older breast cancer survivors experience many ongoing needs - for emotional and tangible support from family and friends, for access to professional counselors, and for new coping strategies to manage fears of recurrence and day-to-day stress [54]. Older women with breast cancer who lack sufficient emotional support have been shown to have poorer self- perceived quality of health and greater difficulty with psychosocial adjustment to cancer [19]. Increasing age and the use of chemotherapy has been known to put older adults at increased risks for toxicities which may require more supportive care [35]. Although it is well known that the risk of breast cancer increases with age, studies on the social support needs of older women with breast cancer are limited. In general, the existing research suggests that older breast cancer patients often rely heavily on their primary care physicians for support [38], yet receive insufficient support because physicians may often communicate poorly and provide inadequate information about breast cancer $[34,44]$. Lack of support from the older breast cancer patient's family may also factor into an unsatisfactory interaction with her physician. [30]. By contrast, women with strong informal support from family and friends are more likely to have higher quality interactions with medical professionals [38]. Older women diagnosed with breast cancer face multiple challenges that may include multiple losses - such as the loss of strength to pursue some of their established routines at home, practical errands, or social contacts [43]. Even when receiving support, these older women still suffer the loss of their functional independence. Finally, older women are more likely to experience ongoing losses of social support from their own age cohort of friends and relatives - to death or illness. With or without health ailments, aging itself involves an inevitable process of enduring many losses and a higher risk for social isolation [3]

Studies about the social support needs of older breast cancer patients from racial/ethnic minority groups are limited, and have focused on patient-provider communication, and treatment decision making. The literature on the experiences of older breast cancer survivors from diverse racial and ethnic backgrounds shows disparities in care $[4,30]$. Existing research suggests that older women from ethnic/racial minority groups experience little helpful communication and information from their physicians due to language barriers and perceived bias [30]. Despite these disparities, older women with breast cancer from racial/ ethnic minority communities are more likely to utilize religious and spiritual faith as an important coping resource $[18,33]$. Studies have shown that for older African American women diagnosed with breast cancer, involvement in a religious faith tradition can provide the breast cancer patient not only with internal emotional strength, but also with external and practical forms of social support, and a sense of belonging to a community [28].

This paper explores how older women react to their breast cancer diagnosis and their subsequent need for social support. It is part of a larger longitudinal study that examined quality of life, spirituality, mood, and social support among breast cancer survivors from 
Table 1 Background of older breast cancer survivors $(n=47)$

\begin{tabular}{|c|c|}
\hline \multicolumn{2}{|l|}{ Background } \\
\hline Mean Age & 72 (range 65-83) \\
\hline $65-70$ & $23(48.9) \%$ \\
\hline $71-75$ & $10(21.2)$ \\
\hline $76-80$ & $9(19.1)$ \\
\hline $80+$ & $5(10.6)$ \\
\hline \multicolumn{2}{|l|}{ Racial background } \\
\hline African American & $17(36.2)$ \\
\hline Asian American & $13(27.7)$ \\
\hline Latina & 7 (14.9) \\
\hline White & $10(21.3)$ \\
\hline Foreign born & $14(30)$ \\
\hline \multicolumn{2}{|l|}{ Marital status } \\
\hline Single & $6(12.8)$ \\
\hline Married/partnered & $17(36.2)$ \\
\hline Divorced & $7(14.9)$ \\
\hline Widowed & $17(36.2)$ \\
\hline \multicolumn{2}{|l|}{ Highest grade completed } \\
\hline 8th grade or less & $3(6.5)$ \\
\hline High School & $4(8.7)$ \\
\hline Some College & $15(32.6)$ \\
\hline College & $11(23.9)$ \\
\hline Post graduate work & $13(28.3)$ \\
\hline Have adult children & $26(86.7 \%)$ \\
\hline Mean number of children & 2.6 (range $0-7$ ) \\
\hline
\end{tabular}

diverse backgrounds. To our knowledge, no studies exist that examine qualitatively the psychosocial experiences of older breast cancer survivors and the meanings of social support for them. This paper contributes to knowledge in the areas of cancer and support by providing new information about the meaning and function of social support in the lives of older women with breast cancer.

\section{Methods}

Participants were recruited through the UCSF Comprehensive Cancer Center Clinic, San Francisco Bay Area breast cancer organizations and the Northern California Cancer Registry. To be eligible for this study, the participant needed to: (1) have had a diagnosis of breast cancer (Stages 0 , I, \& II) within the past four years, (2) have completed primary treatment, and (3) speak/write English, Cantonese, or Spanish. An initial qualitative in-depth interview and quantitative surveys were conducted. For this paper, the investigators used a sub-sample of women over the age of
65 at time at diagnosis for further analyses. The age 65 was used as a selection criterion both because information for this age group is limited and because the incidence of breast cancer for this population is almost twice as high compared to women under the age of 65 [1].

Interviews were conducted at the participant's home or a public place convenient to her. These tape-recorded interviews lasted approximately 1.5 to $2 \mathrm{~h}$, and were conducted in English, Cantonese, and Spanish. The open-ended questions were designed by the research investigators to understand their reactions to their diagnosis and the meaning of social support at diagnosis, during treatment and survivorship. In addition, these questions were then translated and back-translated into Cantonese and Spanish. Participants were asked a series of open-ended questions designed for understanding their reactions to their diagnosis, how they told others about their breast cancer diagnosis, and the reactions of others; the definition and types of social support used at diagnosis, during treatment, after treatment. The audiotapes were then transcribed and translated if necessary (Tables 1 and 2).

\section{Analysis}

This paper follows a grounded theory approach with the focus on a core category of the meaning of reactions to the diagnosis and to social support. Following the procedures

Table 2 Health status of older breast cancer survivors $(n=47)$

\begin{tabular}{lc}
\hline \multicolumn{2}{c}{$n \%$} \\
\hline Perceived health status & $3(7.7)$ \\
Excellent & $14(35.9)$ \\
Very good & $13(33.3)$ \\
Good & $7(17.9)$ \\
Fair & $2(5.1)$ \\
Poor & 27 months (range 5-42 months) \\
Months since diagnosis (mean) & \\
Stage of breast cancer & $26(55.3)$ \\
Stage I & $17(36.2)$ \\
Stage II & $4(8.5)$ \\
DCIS in situ)/stage 0 & $33(70.2)$ \\
Type of treatment & $13(27.7)$ \\
Radiation & $24(51.1)$ \\
Chemotherapy & \\
Hormone therapy & $34(75.6)$ \\
Type of surgery & $11(24.4)$ \\
Lumpectomy & \\
Mastectomy & \\
\hline
\end{tabular}


for grounded theory analysis [49], the investigators first utilized open coding to identify "categories, properties, and dimensional locations" based on the emerging themes found repeatedly throughout the data [49]. The codes that emerged were not forced or fixed. Transcripts were independently reviewed by the research team for commonalities and differences. Next, the transcripts were coded for specific themes within the general category of reactions to diagnosis and subsequent need for social support that appeared repeatedly in the text. Coding was iterative and refinements were made based on our discussions until we reached a consensus on a final definition of each code. Finally, text within a coding category was evaluated to determine whether it accurately fit the definition of the code. The investigators then used axial coding by ways of making relationships between the major categories and subcategories. This was developed and used to give structure and organization to our emerging analysis, and was compared to the key analytic ideas about social support and older women found in the sociological literature. These emerging themes around reactions to the diagnosis and to the need for social support centered on age differences among these women. Thus, verification of the accuracy of the coding scheme (conceptual categories, their definitions, and the observations coded within each category) occurred using both inductive and deductive methods [49].

\section{Findings}

Age differences in reactions to the breast cancer diagnosis

Among older women, a breast cancer diagnosis meant two differing things. For women between 65 to 70 years of age, breast cancer was a wake-up call - a crisis catalyzing a fundamental change in attitude. Like a phone call in the middle of the night, the bad news was unexpected, and came as a shock. For the typical woman in this group, the cancer diagnosis disrupted her basic mental habits of taking her health for granted. The crisis of receiving bad news served as a sobering "reality check" on long-held misperceptions that her body and health should be secure somehow from any serious threat indefinitely. For many of these women, the breast cancer diagnosis marked the first indication that they could be vulnerable to illness. Deepening awareness of this physical vulnerability prompted a difficult but unavoidable process of accepting reality, and making necessary changes in attitude. Many women in this age group had not encountered major health problems prior to breast cancer, and had felt invincible to health problems. The breast cancer diagnosis, however, forced a significant re-evaluation of this attitude. A 67-year-old Latina with Stage I breast cancer stated: "I am more vulnerable to illness. I always though, nah I am never gonna get that. I heard so much about it but there is no one in my family. Well this happened. I have to take that it's like a wake-up call."

The breast cancer diagnosis prompted these women to pause and reflect on their relationship to their own bodies. They underwent an internal process of coming to terms with their limitations. As the first serious illness they encountered in life, the unforeseen crisis of breast cancer provided a catalyst for changes in attitude, and an occasion for reflection and contemplation. A 68-year-old African American with Stage II breast cancer echoed similar thoughts:

I've always been a very optimistic person and enjoyed life and living and this really brought me up short. It said, you know, you're not perfect... things can happen in your life. And that has been the greatest impact, to really make me stop and listen.

In contrast to the 65-70 age group, many women over the age of 70 had started to develop various significant health problems other than breast cancer. A breast cancer diagnosis was an added condition that these women had to contend with. Given their exposure to other health problems and comparative acceptance of the inevitability of death, these older women survivors feared breast cancer less, and considered it less disabling compared to some other illnesses. They saw breast cancer as just a "bump in the road of aging"- - one more among many other health problems that can cause mortality and more importantly, disability. An 81-year-old Chinese American with DCIS stated:

You cannot let an adversity, which breast cancer is, destroy your life. It's so important not just for cancer, but for any of life, you classify it as an adversity in life and you've just gotta go on.... I haven't had it threaten my life to the extent that it would kill me. Life is fraught with peril. [You] just have to handle it.

A 76-year-old White woman with Stage II breast cancer stated:

Well, I think because of your age, you gotta move forward. You can't even slow down. How much longer we got? So whether it be breast cancer or something, I think I would still have the same attitude. It just slowed me down a little.

An 83-year-old African American women with Stage I breast cancer said that her heart condition has affected her life much more than the cancer. A 72-year-old Filipina American with Stage I breast cancer stated that her concern is more about aging in general, and not breast cancer in particular:

I you know sometimes I fumble and it's not because of cancer it is because of my age. They (my friends) come to me and they say, What is happening? Are 
you okay? I tell them I am fine, my trouble is not breast cancer, it's my oldness.

Women over the age of 70 discussed how cancer was a concern, but often said they saw aging in general as the more basic limitation in question. Women saw their bodies aging. All respondents discussed how aging comes with many disabling ailments and that breast cancer is just one among the many, another sign of bodily change. A Caucasian 79-year-old female with Stage II breast cancer stated: "I am getting more aware of my body and I am kinder to it than I used to be."

As a result, for many of these women, the fear of recurrence was not a primary concern, possibly because older women are acutely aware of their mortality and the fleeting nature of life. According to a 78-year-old Caucasian woman with Stage I breast cancer: "I think it's bound to happen. But I'm not concerned about it. I'm not concerned. I would like to live to be 80 because my grandfather died at 79 and he lived longer than anybody else." Another 75-year-old African American woman with Stage I breast cancer stated that she takes 10 pills in the morning for her other health conditions: "I have a lot of other problems in my body, you know, that could possibly take me before the cancer returns". Even when concerns that the cancer might return are expressed, there is an awareness of mortality's inevitability. A 71-year-old African American woman with Stage I breast cancer stated:

I know I had the first Stage of cancer but I've heard of people who had first Stage and still didn't survive, in fact, I've been told about it and people who have had friends who... had first Stages and ... so, I knew thatit was a possibility that I still might not survive, although I expect to die pretty soon anyway, I'm 71 years old.

\section{Self-sufficiency in the face of cancer}

Breast cancer raises a host of fears and concerns about dependence, vulnerability, and the exposure of fallibility and/or weakness - fears that may make older women hesitate to ask for help to meet their needs. This study found that among women over the age of 70 struggled to maintain an appearance of self-sufficiency, older adults often resisted telling others about the cancer. They felt a need to care for themselves, and resisted admitting any need to depend on others. Many of these women over the age of 70 tended to over-rely on a typically American narrative or ideal of self-sufficiency. Several studies have found that one of the greatest fears among older adults is dependence $[5,37]$. Dependence for many of these women meant being needy - unable to complete necessary tasks without reliance or emotional dependence on others. As a result, worries for these women focused less on fears of recurrence and more on the potential of becoming a dependent burden on others. A 75-year-old African American woman with Stage I breast cancer stated: "My biggest fear is having to have somebody to wipe me after I use the bathroom. If I can do that and walk around, I'm fine." Maintaining the appearance of self-sufficiency emotionally and physically was extremely important to these womento the point of posing a barrier to asking for support even when they faced a life-threatening scenario. They wanted to care for themselves and not rely on younger family members for help with their health ailments, whether for cancer treatment, or their other health problems. An 82year-old African American woman with Stage I cancer recalled her past health problems and reluctance to ask others for help:

This summer I had a problem with my heart and I passed out. My grandson was livid. He said, "Why didn't you call me? I was right downstairs. Why didn't you call me?" It didn't occur to me to call him. It did not occur to me to call anybody. It took me two days to call the doctor's office and say, "Oh by the way, I passed out the other day and I thought maybe you would want to know."

Many of these respondents thought that their younger family members, such as nieces, nephews, or adult children were possible sources of support but were also busy with other responsibilities. As a result, many older breast cancer survivors had concerns about reaching out for help from family members. Moreover, many felt that they lacked a supportive network outside of their families that could potentially offer more tangible and instrumental forms of support. At the same time, they wished not to appear emotionally needy. These women assumed that family members did not have the time or inclination to help out or be there emotionally for them, and this assumption influenced how, when, and to what degree these women were willing to ask openly for help to meet their various needs. An 82-year-old Chinese American cancer survivor with DCIS discussed how her perception of the busy lives of her children does not allow her to ask for support:

Each one is wrapped up with their family and I'm not a demanding mother. My oldest son has a daughter and he has his own business, so he's always busy. My oldest daughter has to commute one and half-hours each direction. She then has two boys at night, and she has to help them with their homework. I don't call her up and say, I got a problem. I need a loaf of bread or anything like that. My other daughter just had her first baby and she was really exhausted from the baby crying at night. Though she doesn't live far from here, I don't feel like calling her up to help me either. With my adult kids, I can't even think of saying I'm lonesome. 
Respondents from all racial/ethnic groups discussed not wanting to worry their children. They did not want to burden their already harried sons and daughters even with requests for rides to doctor's appointments, or help with household chores and cooking. An 83-year-old Caucasian woman with Stage I cancer stated: "I don't like to worry my children and I want to be independent and it upset me to think that my son had to take a day off."

In addition to not wanting to burden those closest to them, several women also discussed refraining from asking others for help - often to protect themselves from others' disappointing them. A 79-year-old Caucasian woman with Stage II breast cancer commented that "I realize that why I don't like to ask for help is that I'm afraid they are going to say no." At the same time, participants expressed concerns over the losses they were experiencing in their supportive networks. In many instances, those peers and family members who did offer support were those who were also falling ill and dying. An 83-year-old Caucasian woman with Stage I cancer stated: "A lot of friends and my sister have passed away. So the people that are left are dear friends, but they call [to ask] 'Are you OK?"” Another respondent, a 75-year-old African American woman with Stage I cancer, talked about her adult daughter's dying and her subsequent inability to find other support to replace her daughter's: "I do wonder, you know, what would happen if I get to the point when I can't do things for myself. And on that note, there is nobody that I can depend on." Despite these losses, older breast cancer survivors yearned for connection and community to alleviate the social isolation many of them felt, not simply as a result of breast cancer, but because of the aging process.

Depending on others: learning to ask for support

For all older women, often their worst fear related to diagnosis with breast cancer concerned the disabling effects of chemotherapy treatment. However, for women over the age of 70 there were heightened fears regarding dependency, and fears about the side effects of chemotherapy that caused older women worry about whether they could continue maintaining their lives. A 76-year-old African American with Stage II cancer said her concern was not breast cancer, but chemotherapy and possible dependency:

I was just concerned about if I was going be able to do the chemo because I had heard so many negative things about being sick and... just losing it and I was used to being independent and wondering if I would be able to continue my life the way it had been.

An 82-year-old Caucasian woman with DCIS stated how difficult chemotherapy would have been: "It would have been awful to have to take chemotherapy and be dragging around, half dead." Most of the women in this study were reluctant to ask for assistance and help. The women more likely to learn that they had to accept help were those who had been treated with chemotherapy. Older women with comorbidities who also decide on chemotherapy often have ongoing issues with treatment side effects $[9,53]$. Like younger cancer patients, older cancer patients face similar side-effect symptoms of chemotherapy-such as nausea, fatigue, hair-loss, weight loss, and weight gain — but unlike younger cancer patients, older adults often have other competing health problems that may compound these side effects.

In order to get through chemotherapy, all older women who participated in this study needed access to both emotional and tangible support. They most often relied on family members, friends, church members, and their health care providers to get through treatment. For older women undergoing chemotherapy, there was a need to learn to accept and ask for social support. This was often difficult, especially since these women often were the caregiver for others. A 77-year-old African American woman with stage II breast cancer stated:

I guess I am a very strong person. I just feel like I cannot let myself down where I have to depend on my kids. And so that was the hardest thing. I was pretty strong because I could take care of my husband when he was sick. So I did that for him. I would also go and take care of my son. So the past months it just hit me, Lady you are not that strong as you think.

Others realized that the only way they were able to deal with debilitating side effects of chemotherapy was through the support of others. A 74-year-old Chinese American woman with Stage II breast cancer said that she "...had a lot of support. The staff was wonderful, these nurses and doctors were always looking out for me, and my family. It's just a nasty experience and if I didn't have the support it would have been worse." Many respondents talked about the need to just "put it out there." Even for more youngerolder (under 70) women, there still was hesitancy in asking for support. A 66-year-old Caucasian woman with Stage II breast cancer stated, "People give back. They are great. They're right there for you, but you have to ask for it sometimes." Once the cancer patient disclosed, people automatically showed concern and gave support in any way they could. An 82-year-old African American Stage II cancer survivor discussed what it was like to finally talk about her diagnosis:

When you're closed up... in a knot...thinking that you're the only one that has this ugly disease, you need to talk about it. Because it'll drive you... when I first heard it...I didn't think at all. I didn't think. All I 
wanted to do was take some pills. I just wanted to go to sleep. I wanted to put myself out of my misery. But as the days kept going, you know... [After] the initial hearing of the word, the big ugly " $\mathrm{C}$ " word...don't stay closed up in the bed in the room. Talk about it...you would be surprised how many people will call you and let you know, you have our support. What do you want me to do? Blah, blah, blah ya' know? And I had that. I still get it to this day.

Others talked about the emotional support they received from other breast cancer survivors who had already been through it. Older women who had to undergo a mastectomy and chemotherapy echoed the importance of emotional support. A 75-year-old Chinese American woman with Stage II cancer who underwent chemotherapy discussed the support she received: "I have wonderful friends. They call me. They come see me. They send me flowers, send me cards."

Although only a few older women in this study mentioned support groups or other types of networks, several women in this study talked about how their religious organization was extremely supportive. Older women tend to rely on religious traditions and support from their religious and faith communities to get through their diagnosis and treatment $[28,33]$. Several older women discussed the importance of spiritual support from their religious communities, and how that enabled them to get through diagnosis and treatment. A 75-year-old African American with Stage II breast cancer stated how her church community supported her and how she found others in her church who were cancer survivors and supportive:

I started getting calls from all over the state, letting me know that they were praying with me, and then discovered that there were others who had cancer, ... who were survivors that I did not know were survivors, and I had that connection for all of this time. I still have that...connection. A lot of sisters would call and pray with me on the phone... before I went in as well as after I had the surgery.

For many older women undergoing chemotherapy, tangible support was crucial. Often, social support for older breast cancer patients is provided by those closest in proximity including neighbors, friends, and adult sons and daughters residing nearby. For example, many women undergoing chemotherapy often relied on immediate family members to provide assistance. Sometimes adult children living nearby would accompany their mothers to their surgery appointments. A 75-year-old Chinese American with Stage II cancer stated that during her chemotherapy she relied on her family for tangible support:

My son and my daughter-in-laws ... they do everything for me-washing — everything ... [they] buy food for me, because I cannot carry [it], they cook for me, they clean my kitchen, you know they do everything for me.

There was a clear need for help among many of the older women experiencing chemotherapy, but many felt reluctant to ask for help. Although many mentioned family members as a source of tangible support, many found it difficult to rely entirely on family members. A 73-year-old Chinese immigrant with Stage II breast cancer stated: "I still depended on myself. There weren't people who could constantly help me out. The ones who could help me were at work. That's what was expected and that is how I prepared myself. I didn't ask for extra help." Even when friends offered to clean her house or do the laundry, there was still hesitancy about accepting support from others. A 67-year-old African American woman with Stage I breast cancer who had undergone chemotherapy and experienced problems of with fatigue talked about difficulties receiving the support that was offered. She mentioned that her friend was willing to help and offered to change sheets, towels, and wash the kitchen floor but she had said: "I said oh if I need you, I will call you, I promise." A 76-year-old African American woman with Stage II breast cancer talked about the difficulty of asking for tangible help from her neighbors: "The first time I had my treatment and I did ask my neighbor next door to go with me...that was [hard]...you know when you have been independent so long it is kind of hard to ask someone to do something for you." Across the different racial/ethnic groups, older women with breast cancer had difficulties asking and receiving social support as they processed and endured their cancer diagnosis and treatment. Women often had to learn to ask for and accept emotional and tangible support.

\section{Discussion/conclusion}

The purpose of this paper was to examine qualitatively the reactions to a breast cancer diagnosis and subsequent need for social support in the lives of older breast cancer survivors from racially and ethnically diverse populations. As the findings of this study demonstrate, a breast cancer diagnosis for older women can result in a range of challenges regarding health and vulnerability which are often associated with concerns about dependency. Older adults over the age of 70 were more concerned about the death of loved ones, their own death from other illnesses, disability, and other losses in life as a whole, than about breast cancer specifically. The fear of recurrence that is salient among women younger than 70 breast cancer survivors [6] was not the older women's primary concern. With increasing age, fears around cancer recurrence feel 
less threatening when compared to the fears of relatively younger breast cancer survivors $[6,15]$. Rather, the greater concerns for all older women were about maintaining independence and quality of life. Many older women have learned to cope with a cancer diagnosis through acceptance [14]. Among elderly cancer survivors, acceptance, positive reframing and religion are the most common coping responses to cancer [10].

Across the different racial and ethnic groups, older women felt compelled to cope with the illness and treatment on their own and not depend on others, even while others continued to depend on them for various household tasks and emotional needs. The greatest fear among older adults is dependence. Older individuals often feel a need to maintain their self-sufficiency and autonomy in the face of their cancer diagnosis. All respondents in this study expressed a strong need not to appear vulnerable and dependent, but to make it through cancer without having to depend on too many people. Other studies have reported similar findings, that older women with breast cancer were more concerned about the way treatment might impact quality of life and independence [27]. However, this study provides a qualitative perspective on how even among older adults that there are differences in how they react to their diagnosis and their needs for social support.

The findings of this study provide an understanding of the importance of support for older adults facing cancer. Although all the older women in this study were more concerned with the potential disabling impact of chemotherapy, the older woman who underwent chemotherapy needed and welcomed support from their family, friends, and health care providers. When faced with the prospect of invasive treatments like mastectomy, chemotherapy, and radiation, older women overcame their reluctance to admit their vulnerabilities and sought out support. Older adults generally have difficulty asking for help and have traditionally preferred not to seek others' help if they are able [2]. The women in this study who faced chemotherapy often had to seek out others for tangible, informational, emotional, and spiritual support. In this study, over $25 \%$ of women received chemotherapy and those receiving chemotherapy welcomed support from family and friends. Many of the older women in this cohort sought out support from members and/or leaders of their religious institutions. This finding is consistent with the literature that demonstrates that spirituality and religious institutions play a supportive role for older women facing cancer [39]. In this study, asking for tangible support was often difficult for older women, yet was important to their treatment and quality of life. Previous researchers studying older adults undergoing chemotherapy have found that older adults often faced losses in terms of normal tasks and functions due to chemotherapy and often adapted by asking for support [21].
Many of these women continued to help and support others in their network, even while expecting to face alone their own challenges, not only those associated with breast cancer treatment but also all the challenges that are present for aging bodies in general. The simple act of acknowledging that they were getting older, along with an increase in their limitations and vulnerabilities, often marked a major milestone for many of these women in terms of admitting to their needs for help.

\section{Limitations}

The main limitation of this study lies in the relatively small sample size. Studies with larger sample sizes might find differences between size, location, and quality of social support networks. A further limitation is that the women were interviewed on average 2 years after completion of therapy, so their recall of what happened during cancer therapy may be less accurate than if they had been interviewed sooner.

\section{Implications}

Dependency is the greatest fear, given that maintaining independence in the face of illness has often been seen as important to quality of life among older adults [20]. For older cancer patients, the loss of independence has been shown as a contributing risk factor to psychological distress [26]. Despite this ideal of maintaining one's independence even in the face of illness, this study shows that older adults facing breast cancer need support-especially those who are facing chemotherapy. Several studies examining social networks, support, and breast cancer have shown that meeting these needs for support is associated with better survival outcomes among women diagnosed with breast cancer [21, 31]. Moreover, more than $20 \%$ of women aged 65 and older in the United States diagnosed with breast cancer underwent adjuvant chemotherapy [17] which resulted in a greater need for support. Although older women often feel reluctant to depend on others during their breast cancer treatment, various forms of support are needed to get through diagnosis, treatment, and posttreatment periods.

At a time when older women with breast cancer are often undergoing losses of their existing support from peers and family members, health care providers can play a crucial role in helping older women cope with breast cancer [11]. Improved education and information from health care providers can enhance social support and may buffer the impact of a breast cancer diagnosis and its subsequent treatment and improve the overall survivorship experience 
among older adults $[11,43]$. At the same time, there also needs to be additional education on the impact of breast cancer treatment such as chemotherapy not only on the older woman patient but also on her informal and formal support networks. It is important to inform the patient's social network about the emotional barriers related to telling others of one's diagnosis [55] and the difficulties asking for needed social support. Also, it is advisable to educate the patient about the importance of asking for social support and to help her identify ways of receiving such support. The findings in this paper have implications for older women with breast cancer and their need for supportive networks, both formal and informal, not only at the time of a breast cancer diagnosis but also during treatment and afterwards.

Acknowledgments This research was supported by a Research Infrastructure in Minority Institutions (RIMI) grant 5 P20 MD000544-02 from the National Center for Minority Health and Health Disparities, National Institutes of Health, to San Francisco State University. The authors would like to acknowledge the help of our research assistants: Yaffa Alter, Heather Law, Erin McCoy, Ana Freire, Mariaelena Gonzalez, Regina Lagman, Mabel Lam, Beverly Lynn, Jennifer Nazareno, Sann Situ, Chris Van Onselen, Jacqueline Bishop, Shelley Volz, Ivy Wong, Gloria Boehm, Tina Chan, Julie Armin, Ann Gilliard, Qiu Chen, Sachiko Reed, Jonathan Lee, and Laureen Hom. The authors also appreciate the editorial assistance of Emily H. Zimmerman. The collection of cancer incidence data used in this study was supported by the California Department of Public Health as part of the statewide cancer reporting program mandated by California Health and Safety Code Section 103885; the National Cancer Institute's Surveillance, Epidemiology and End Results Program under contract N01-PC-35136 awarded to the Northern California Cancer Center, contract N01-PC-35139 awarded to the University of Southern California, and contract N02-PC-15105 awarded to the Public Health Institute; and the Centers for Disease Control and Prevention's National Program of Cancer Registries, under agreement \#U55/CCR921930-02 awarded to the Public Health Institute. The ideas and opinions expressed herein are those of the author(s) and endorsement by the State of California, Department of Public Health the National Cancer Institute, and the Centers for Disease Control and Prevention or their Contractors and Subcontractors is not intended nor should be inferred.

Open Access This article is distributed under the terms of the Creative Commons Attribution Noncommercial License which permits any noncommercial use, distribution, and reproduction in any medium, provided the original author(s) and source are credited.

\section{References}

1. American Cancer Society (2006) Cancer facts and figures. American Cancer Society, Oakland

2. Areán PA, Alvidrez J, Barrera A, Robinson GS, Hicks S (2002) Would older medical patients use psychological services? Gerontologist 42:392-398

3. Ashing-Giwa KT (2005) Can a culturally responsive model for research design bring us closer to addressing participation disparities? Lessons learned from cancer survivorship studies. Ethn Dis 15:130-137

4. Ashida S, Palmquist AEL, Basen-Engquist K, Singletary SE, Koehly LM (2009) Changes in female support network systems and adaptation after breast cancer diagnosis: differences between older and younger patients. Gerontologist 49:549-559

5. Bates M (1996) The many faces of dependency in old age. Cambridge University Press, London

6. Bloom JR, Stewart SL, Chang S, Banks P (2004) Then and now: quality of life of young breast cancer survivors. Psycho-Oncology 13(3):147-160

7. Bloom J, Stewart SL, Johnston M, Banks P, Fobair P (2001) Sources of support and the physical and mental well-being of young women with breast cancer. Soc Sci Med 53(11):1513-1524

8. Bouchardy C, Rapiti E, Blagojevic S, Vlastos AT, Vlastos G (2007) Older female cancer patients: importance, causes, and consequences of undertreatment. J Clin Oncol 25(14):18581869

9. Browall M, Ahlberg K, Persson L-O, Karlsson P, Danielson E (2008) The impact of age on Health-Related Quality of Life (HRQoL) and symptoms among postmenopausal women with breast cancer receiving adjuvant chemotherapy. Acta Oncol 47:202-215

10. Carver CS, Pozo C, Harris SD, Noriega V, Scheier MF, Robinson DS, Ketcham AS, Moffat FL Jr, Clark KC (1993) How coping mediates the effect of optimism on distress: a study of women with early stage breast cancer. J Pers Soc Psychol 65:375-390

11. Clough-Gorr KM, Ganz PA, Silliman RA (2007) Older breast cancer survivors: factors associated with change in emotional well-being. J Clin Oncol 25:1334-1340

12. Cohen S, Gottlieb B, Underwood L (2000) Social relationships and health. In: Cohen S, Underwood L, Gottlieb B (eds) Social support measurement and intervention. Oxford University Press, New York, New York, pp 3-28

13. Cohen S, Syme LS (1985) Social support and health. Academic, Orlando, Florida

14. Deimling GT, Bowman KF, Sterns S, Wagner LJ, Kahana B (2006) Cancer-related health worries and psychological distress among older adult, long-term cancer survivors. Psychooncology 15:306-320

15. Deimling GT, Kahana B, Bowman KF, Schaefer ML (2002) Cancer survivorship and psychological distress in later life. Psychooncology 11:479-494

16. Deshields T, Tibbs T, Fan MY, Taylor M (2006) Differences in patterns of depression after treatment for breast cancer. Psychooncology 15(5):398-406

17. Doyle JJ, Neugut AI, Jacobson JS, Grann VR, Hershman DL (2005) Chemotherapy and cardiotoxicity in older breast cancer patients: a population-based study. J Clin Oncol 23:85978605

18. Feher S, Maly RC (1999) Coping with breast cancer in later life: the role of religious faith. Psychooncology 8:408-416

19. Ganz PA, Guadagnoli E, Landrum MB, Lash TL, Rakowski W, Silliman RA (2003) Breast cancer in older women: quality of life and psychosocial adjustment in the 15 months after diagnosis. $\mathrm{J}$ Clin Oncol 21:4027-4033

20. Gignac M, Cott C, Badley EM (2000) Adaptation to chronic illness and disability and its relationship to perceptions of independence and dependence. J Gerontol B Psychol Sci Soc Sci 55:P362-P372

21. Goodwin JA (2007) Older adults' functional performance loss and adaptation during chemotherapy. Geriatr Nurs 28:30-376

22. Goodwin P, Leszcz M, Ennis M et al (2001) The effect of group psychosocial support on survival in metastatic breast cancer. $\mathrm{N}$ Engl J Med 345:1719-1726 
23. Hegel MT, Moore CP, Collins ED, Kearing S, Gillock KL, Riggs RL, Clay KF, Ahles TA (2006) Distress, psychiatric syndromes, and impairment of function in women with newly diagnosed breast cancer. Cancer 107(12):2924-2931

24. Holland JC, Reznik I (2005) Pathways for psychosocial care of cancer survivors. Cancer 104(11 Suppl):2624-2637

25. House JS, Khan R (1985) Measures and concepts of social support. In: Cohen S, Syme SL (eds) Social support and health. Academic, Orlando, FL, pp 83-108

26. Hurria A, Li D, Hansen K, Patil S, Gupta R, Nelson C, Lichtman SM, Tew WP, Hamlin P, Zuckerman E, Gardes J, Limaye S, Lachs M, Kelly E (2009) Distress in older patients with cancer. J Clin Oncol 27:4346-4351

27. Husain LS, Collins K, Reed M, Wyld L (2008) Choices in cancer treatment: a qualitative study of the older women's $(>70$ years) perspective. Psychooncology 17:410-416

28. Idler EL (1987) Religious involvement and the health of the elderly: some hypotheses and an initial test. Social Forces 66:226238

29. Knobf MT (2007) Psychosocial responses in breast cancer survivors. Semin Oncol Nurs 23:71-83 Review

30. Kreling B, Figueiredo MI, Sheppard VL, Mandelblatt JS (2006) A qualitative study of factors affecting chemotherapy use in older women with breast cancer: barriers, promoters, and implications for intervention. Psychooncology 15(12):1065-1076

31. Kroenke C, Kubzansky LD, Schernhammer ES, Holmes MD, Kawachi I (2006) Social networks, social support, and survival after breast cancer diagnosis. J Clin Oncol 24:1105-1111

32. Leedham B, Ganz PA (1999) Psychosocial concerns and quality of life in breast cancer survivors. Cancer Invest 17:342-348 Review. No abstract available

33. Levine EG, Yoo G, Aviv C, Ewing C, Au A (2007) Ethnicity and spirituality in breast cancer survivors. J Cancer Surviv Sep 1:212225

34. Liang W, Burnett CB, Rowland JH, Meropol NJ, Eggert L, Hwang Y, Silliman RA, Weeks JC, Mandelblatt JS (2002) Communication between physicians and older women with localized breast cancer: implications for treatment and patient satisfaction. J Clin Oncol 20:1008-1016

35. Lichtman SM (2006) Therapy insight: therapeutic challenges in the treatment of elderly cancer patients. Nat Clin Pract Oncol 3:86-93

36. Loerzel VW, McNees P, Powel LL, Su X, Meneses K (2008) Quality of life in older women with early-stage breast cancer in the first year of survivorship. Oncol Nurs Forum 35:924-932

37. Mack R, Salmoni A, Viverais-Dressler G, Porter E, Garg R (1997) Perceived risks to independent living: the views of older, community-dwelling adults. Gerontologist 37:729-736

38. Mandelblatt J, Kerner JF (2002) Variations in breast carcinoma treatment in older medicare beneficiaries. Cancer 95(7):1401-1414

39. Musick MA, Koenig H, Hays J, Cohen H (1998) Religious activity and depression among community-dwelling elderly persons with cancer: the moderating effect of race. J Gerontol B Psychol Sc Soc Sci 53B:S218-S227
40. Muss HB, Berry DA, Cirrincione CT, Theodoulou M, Mauer AM, Kornblith AB, Partridge AH, Dressler LG, Cohen HJ, Becker HP, Kartcheske PA, Wheeler JD, Perez EA, Wolff AC, Gralow JR, Burstein HJ, Mahmood AA, Magrinat G, Parker BA, Hart RD, Grenier D, Norton L, Hudis CA, Winer EP, the CALGB Investigators (2009) Adjuvant chemotherapy in older women with early-stage breast cancer. N Engl J Med 360:2055-2065

41. Newsom JT, Schulz R (1996) Social support as a mediator in the relation between functional status and quality of life in older adults. Psychol Aging 11:34-44

42. Paskett ED (2008) Breast cancer-related lymphedema: attention to a significant problem resulting from cancer diagnosis. J Clin Oncol 26:5666-5667 Epub 2008 Nov 10

43. Pillemer K, Glasgow N (2000) Social integration and aging: background and trends. Johns Hopkins University Press, Baltimore, Maryland

44. Posma ER, van Weert JC, Jansen J, Bensing JM (2009) Older cancer patients' information and support needs surrounding treatment: an evaluation through the eyes of patients, relatives and professionals. BMC Nurs 8:1

45. Robb C, Haley WE, Balducci L, Extermann M, Perkins EA, Small BJ, Mortimer J (2007) Impact of breast cancer survivorship on quality of life in older women. Crit Rev Oncol Hematol 62:84-91 Epub 2006 Dec 22

46. Sammarco A (2003) Quality of life among older survivors of breast cancer. Cancer Nurs 26(6):431-438

47. Silliman RA, Guadagnoli E, Weitberg AB, Mor V (1989) Age as a predictor of diagnostic and initial treatment intensity in newly diagnosed breast cancer patients. J Gerontol 44:M46-M50

48. Spiegel D (1992) Conserving breasts and relationships. Health Psychol 11:347-348 No abstract available

49. Strauss AL, Corbin JM (1990) Basics of qualitative research: grounded theory procedures and techniques. Sage, Newbury Park, CA

50. Tallarico M, Figueiredo M, Goodman M, Kreling B, Mandelblatt J (2005) Psychosocial determinants and outcomes of chemotherapy in older women with breast cancer: what do we know? What do we need to know? Cancer J 11(6):518-528

51. Thewes B, Butow P, Girgis A, Pendlebury S (2004) The psychosocial needs of breast cancer survivors; a qualitative study of the shared and unique needs of younger versus older survivors. Psychooncology 13:177-189

52. Wyatt GK, Friedman LL (1998) Physical and psychosocial outcomes of midlife and older women following surgery and adjuvant therapy for breast cancer. Oncol Nurs Forum 25(4):761-768

53. Wyld L, Reed M (2007) The role of surgery in the management of older women with breast cancer. Eur J Cancer 43:2253-2263 [Epub 2007 Sep 29.]

54. Yancik R, Wesley MN, Ries LA, Havlik RJ, Edwards BK, Yates JW (2001) Effect of age and comorbidity in postmenopausal breast cancer patients aged 55 years and older. JAMA 285:885-892

55. Yoo GJ, Aviv C, Levine EG, Ewing C, Au A (2009) Emotion work: disclosing cancer. Supportive Cancer Care. doi:10.1007/ s00520-009-0646-y 